Brief Original Article

\title{
Tuberculosis with malaria or HIV co-infection in a large hospital in Luanda, Angola
}

\author{
Emília Valadas ${ }^{1}$, Augusto Gomes ${ }^{1,2}$, Ana Sutre ${ }^{1}$, Sara Brilha ${ }^{1}$, Afonso Wete ${ }^{2}$, Thomas Hänscheid ${ }^{3}$, \\ Francisco Antunes ${ }^{1}$
}

${ }^{1}$ Clínica Universitária de Doenças Infecciosas e Parasitárias, Faculdade de Medicina da Universidade de Lisboa, Portugal

${ }^{2}$ Hospital Sanatório de Luanda, Luanda, Angola

${ }^{3}$ Instituto de Microbiologia and Instituto de Microbiologia Molecular, Faculdade de Medicina da Universidade de Lisboa, Portugal

\begin{abstract}
Introduction: Three major public health problems, tuberculosis, malaria and HIV/AIDS, are widespread in Angola, often as co-infections in the same individual. In 2009, it was assumed that 44,151 new cases of TB occurred in Angola. Interestingly, interventions such as treatment/prevention of malaria appear to reduce mortality in HIV-infected and possibly TB co-infected patients. However, despite the seriousness of the situation, current data on TB and co-infection rates are scarce.

This study aimed to characterize all TB cases seen at the Hospital Sanatório de Luanda, and to determine the co-infection rate with HIV and/or malaria.

Methodology: This retrospective study collected demographic, diagnostic and clinical data from all patients admitted during 2007.

Results: A total of 4,666 patients were admitted, of whom 1,906 (40.8\%) were diagnosed with TB. Overall, 1,111 patients (58.3\%) were male and most patients $(\mathrm{n}=1302,68.3 \%)$ were adults ( $\geq 14$ years). The rate of HIV co-infection was $37.4 \%$ ( $\mathrm{n}=712)$. Malaria was diagnosed during admission and hospital stay in 714 patients (37.5\%), with Plasmodium falciparum the predominant species. Overall mortality was $15.2 \%$ $(\mathrm{n}=290)$.

Conclusions: Because Luanda does not have the infrastructure to perform culture-based diagnosis of TB, confirmation of TB is problematic. The HIV-co-infection rate is high, with $37.4 \%$ of patients requiring integrated approaches to address this problem. With more than $1 / 3$ of the TB patients co-infected with malaria, even during the hospital stay, the prevention of malaria in TB patients appears to be an effective way to reduce overall mortality.
\end{abstract}

Key words: tuberculosis; HIV; malaria; co-infection; Angola

J Infect Dev Ctries 2013; 7(3):269-272.

(Received 19 April 2012 - Accepted 26 September 2012)

Copyright (C) 2013 Valadas et al. This is an open-access article distributed under the Creative Commons Attribution License, which permits unrestricted use, distribution, and reproduction in any medium, provided the original work is properly cited.

\section{Introduction}

Angola is Africa's seventh largest country. Approximately a quarter of the population, 4.8 million, live in the capital, Luanda [1]. Two thirds of Luanda's inhabitants live in crowded neighborhoods, often in so-called "musseques", and large parts of the population have difficulty in accessing basic health care, clean water, or electricity [2]. Almost half of the population $(41.5 \%)$ lives below the poverty level, and life expectancy is low (40 and 43 years for men and women, respectively) [1].

According to the Angolan authorities, the tuberculosis (TB) situation is alarming and constitutes a major public health problem. The official number of new TB cases grew from 38,317 in 2005 to 44,151 in 2009 [3]. However, as direct observational therapy, short-course (DOTS) coverage increased from $43.0 \%$ to $64.0 \%$ between 2002 and 2008 , treatment success also increased from $68.0 \%$ in 2002 to $73.1 \%$ in 2008 , albeit below the WHO target of $85.0 \%$ [4]. Official data on HIV-TB co-infection rates show large geographic variation from $2.8 \%$ in the northern province of Cabinda, to $6.0 \%$ in Luanda, and up to $15.6 \%$ in the province of Benguela [5]. However, in a country where culture confirmation of TB is almost unavailable, little is known about many aspects of TB.

In the capital, individuals with suspected TB are sent to Hospital Sanatório de Luanda (HSL), a reference hospital near Luanda. The aim of this study was to obtain better knowledge of the TB situation in Luanda by characterizing the clinical presentation and methods most often used to diagnose TB, HIV and 
malaria co-infection, as well as alternative ways to diagnose this problem in our population.

\section{Methodology}

Clinical files from all patients admitted during 2007 to the HSL were analyzed retrospectively. Demographic data, methods used for the diagnosis of $\mathrm{TB}$, treatment and in-hospital mortality, as well as HIV status and malaria diagnosis, were collected. TB diagnosis was based on clinical and radiological findings, Mantoux test, and sputum microscopy. HIV serology was performed for all patients, using rapid diagnostic tests (Determine, Abbott Laboratories, Abbott Park, Illinois, USA) and malaria was diagnosed by standard thick and thin film microscopy.

This study was authorized by the Direcção Geral from the HSL, Angola, and the Ethics Committee of the Faculdade de Medicina da Universidade de Lisboa, Portugal.

\section{Results}

During the 12-month period of the study, a total of 4,666 patients were admitted to HSL, of whom 1,906 $(40.8 \%)$ were diagnosed with TB. Overall, 1,111 patients $(58.3 \%)$ were male and most patients $(\mathrm{n}=$ $1,302,68.3 \%)$ were adults ( $\geq 14$ years, mean: 32 years; range: 14-75) (Figure). Diagnosis in adults was based on clinical evaluation and changes on the chest X-ray only in $492(37.7 \%)$ in contrast to 810 patients $(62.2 \%)$ with a positive Ziehl-Neelsen $(\mathrm{ZN})$ stain. Of those with a positive ZN stain, only 441 (54.4\%) were considered new cases, while $220(27.2 \%)$ were classified as relapse, $29(3.6 \%)$ as failure, and 120 $(14.8 \%)$ as reappeared.

TB was diagnosed in 604 of $606(99.7 \%)$ children $(<14$ years old) (Figure). Diagnosis was based on clinical evaluation, chest X-ray, and Mantoux test with a diameter of induration of at least $10 \mathrm{~mm}$. Nineteen children $(3.1 \%)$ had lymph node TB while all others were diagnosed with pulmonary or disseminated TB.

HIV infection was diagnosed in 712 TB patients (37.4\%). Of note, Plasmodium falciparum malaria was diagnosed in 714 of the 1,906 patients with TB $(37.5 \%)$.

Overall, 290 patients with TB (15.2\%) died in hospital. Twenty-seven of these patients were HIV infected and three had malaria.

\section{Discussion}

This brief report highlights several important issues concerning TB in Angola. Only $62.2 \%$ of adult TB patients and only $54.4 \%$ of new cases had a

Figure. Rate of TB diagnosis in children $(<14$ years old) and adults $(\geq 14$ years old) at the HSL

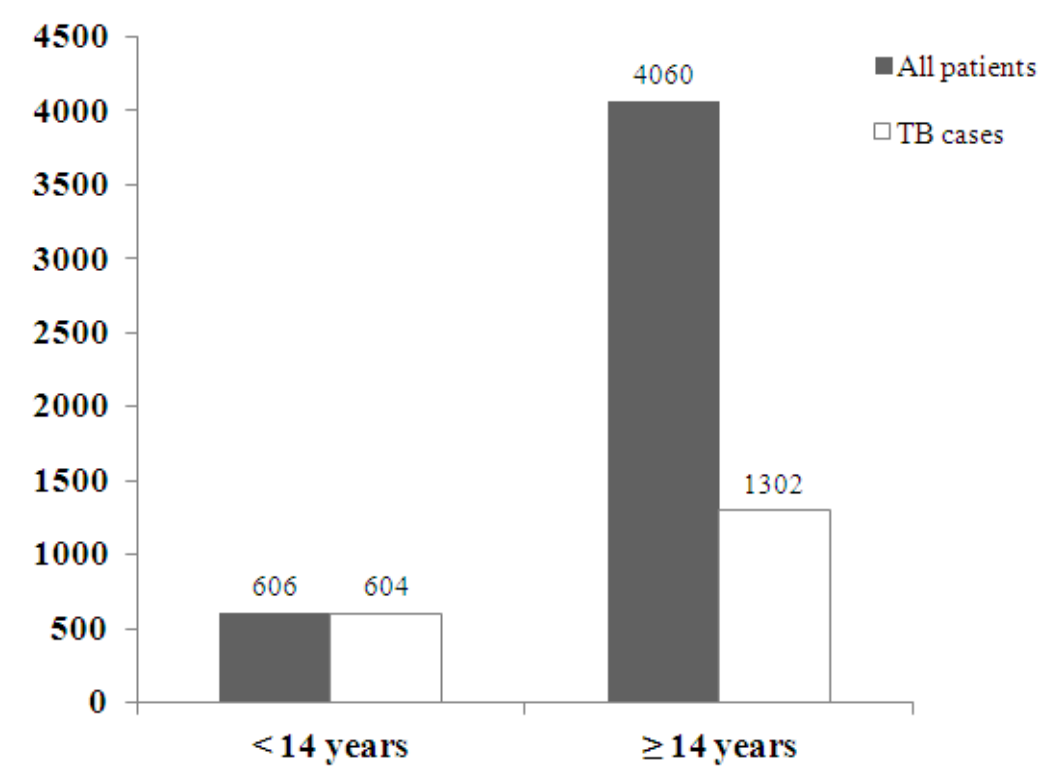

Grey bars represent the total number of patients admitted to the Hospital Sanatório de Luanda and white bars represent patients with a TB diagnosis. 
positive ZN smear [6,7]. Furthermore, only a third of adults referred to the central TB hospital were diagnosed with TB. Contrary to this, children may have been over-diagnosed, with a rate of nearly $100 \%$, which can be explained by the fact that the diagnosis was primarily based on Mantoux testing, clinical signs, and X-ray changes, and not on microscopy results $[8,9]$.

Of particular concern is that only half of the adult patients were considered as new cases, and almost one third as relapses or failures. Certainly, this may point to low adhesion to treatment or problems in DOTS implementation. In fact, while the National Program for the Control of TB in Angola began in 1981, it was implemented in only $8.6 \%$ of the health-care institutions in 2007 [5]. Moreover, distribution of antiTB drugs in the country seems to be irregular; even if drugs are available in Luanda, this is not necessarily true for the rest of the country [5].

However, and more worryingly, the high rate of relapses and failures may also reflect existing but unknown drug- or multidrug-resistance. This situation might explain why $15.0 \%$ of all patients died in hospital, despite a rather low HIV-co-infection rate of $37.4 \%$. Furthermore, the overall HIV-co-infection rate was lower than the rates seen in other southern African countries such as Mozambique (66.0\%), Gabon (59\%), or South Africa (58.0\%) [5].

Interestingly, $37.5 \%$ of the TB patients also had malaria, a finding which may be of importance in the light of recent data, showing that malaria infection may exacerbate TB [10].

The results confirm the importance of improving TB diagnosis in Angola. Better microscopy results and implementation of the GeneXpert test, culture to increase detection rates and drug sensitivity testing are highly desirable [11]. Concerning microscopy, the use of auramine $\mathrm{O}$ and low-cost Light-Emitting-Diode (LED) fluorescent microscopes [12] are an inexpensive way to increase sensitivity $[13,14]$. Possibly, the novel GeneXpert test might have provided valuable information about many patients. Additionally, mycobacterial culture should be more widely available to increase case detection and allow sensitivity testing of all drugs. However, work with resistant Mycobacterium tuberculosis cultures requires biosafety level 3 facilities, which are expensive to build and maintain [15]. On the other hand, novel methods, such as the Microscopic Observation Drug Sensitivity (MODS) assay, are also fast and efficient, inexpensive, and already in use in some resource-poor countries, because they require only a biosafety level 2 facility [16].

This study provides much needed data with which to plan TB control efforts in Luanda, and underscores the urgency in improving laboratory diagnostic capacity.

\section{References}

1. World Health Organization Global Task Force for Cholera Control, 2009 (2009) Cholera Country Profile Angola. Geneva, Switzerland: World Health Organization. Available at:

http://www.who.int/cholera/countries/AngolaCountryProfile2 009.pdf (accessed 14 December 2011).

2. AfDB/OECD African Economic Outlook 2007 (2007) Angola report. Issy les Moulineaux France: OECD Development Centre. Available at: http://www.oecd.org/dataoecd/26/16/38561655.pdf (accessed 14 December 2011).

3. World Health Organization (2011) Global Tuberculosis Control. WHO Report. WHO/HTM/TB/2010.7. Geneva, Switzerland: WHO, 2011.

4. World Health Organization (2009) Country profile: Strategic Plan of the National TB Control Program, Ministry of Health, Luanda, 2008.

5. http://transition.usaid.gov/our_work/global_health/id/ tuberculosis/countries/africa/angola_profile.html.

6. Wilkinson D, De Cook KM, Sturm AW (1997) Diagnosing tuberculosis in a resource-poor setting: the value of a trial of antibiotics. Trans R Soc Trop Med Hyg 91: 422-424.7.

Mfinanga GS, Ngadaya E, Mtandu R, Mutayoba B, Basra D, Kimaro G, Chonde TM, Ngowi P, Mfaume S, Kilale AM, Egwaga S, Kitua AY (2007) The quality of sputum smear microscopy diagnosis of pulmonary tuberculosis in Dar es Salaam, Tanzania. Tanzan Health Res Bull 9: 164-168.

8. Khan EA and Starke JR (1995) Diagnosis of tuberculosis in children: increased need for better methods. Emerg Infect Dis 1: $115-123$.

9. Marais BJ, Graham SM, Cotton MF, Beyers N (2007) Diagnostic and management challenges for childhood tuberculosis in the era of HIV. J Infect Dis 196: S76-85.

10. Colombatti R, Penazzato M, Bassani F, Vieira CS, Lourenço AA, Vieira F, Teso S, Giaquinto C, Riccardi F (2011) Malaria prevention reduces in-hospital mortality among severely ill tuberculosis patients: a three-step intervention in Bissau, Guinea-Bissau. BMC Infect Dis11: 57.

11. Scott LE, McCarthy K, Gous N, Nduna M, Van Rie A, Sanne I, Venter WF, Duse A, Stevens W (2011) Comparison of Xpert MTB/RIF with other nucleic acid technologies for diagnosing pulmonary tuberculosis in a high HIV prevalence setting: a prospective study. PLoS Med 8: e1001061.

12. Hänscheid $T$ (2008) The future looks bright: low-cost fluorescent microscopes for detection of Mycobacterium tuberculosis and Coccidiae. Trans R Soc Trop Med Hyg 102: 520-521.

13. Steingart KR, Henry M, Ng V, Hopewell PC, Ramsay A, Cunningham J, Urbanczik R, Perkins M, Aziz MA, Pai M (2006) Fluorescence versus conventional sputum smear microscopy for tuberculosis: a systematic review. Lancet Infect Dis 6: 570-581. 
14. Marais BJ, Brittle W, Painczyk K, Hesseling AC, Beyers N, Wasserman E, van Soolingen D, Warren RM (2008) Use of light-emitting diode fluorescence microscopy to detect acidfast bacilli in sputum. Clin Infect Dis 47: 203-207.

15. Hänscheid $T$ and Grobusch MP (2010) Biosafety and tuberculosis laboratories in Africa. Lancet Infect Dis 10:582583.

16. Moore DA, Evans CA, Gilman RH, Caviedes L, Coronel J, Vivar A, Sanchez E, Piñedo Y, Saravia JC, Salazar C, Oberhelman R, Hollm-Delgado MG, LaChira D, Escombe AR, Friedland JS (2006) Microscopic-observation drugsusceptibility assay for the diagnosis of TB. N Engl J Med 355: 1539-1550.

\section{Corresponding author}

Emília Valadas, MD, MSc, $\mathrm{PhD}$

Laboratório de Diagnóstico Molecular de Doenças Infecciosas Clínica Universitária de Doenças Infecciosas e Parasitárias

Faculdade de Medicina, Universidade de Lisboa

1649-028 Lisbon, Portugal

Telephone: +35121 7805283, Fax: +351 217976224

Email: evaladas@fm.ul.pt

Conflict of interests: No conflict of interests is declared. 